\title{
PENGARUH KOMITMEN ORGANISASI, LINGKUNGAN KERJA DAN KEPUASAN KERJA TERHADAP INTENSI TURNOVER PEGAWAI PADA DINAS PERIKANAN KOTA TANJUNGBALAI
}

\author{
${ }^{1}$ Mahnim Pane, ${ }^{2}$ Poltak Parluhutan Simarmata, ${ }^{3}$ Nufrizal. \\ ${ }^{1,2,3}$ Universitas Islam Sumatera Utara \\ ${ }^{1}$ mahnim.pane@gmail.com, ${ }^{2}$ poltak.parluhutan@gmail.com, ${ }^{3}$ nufrizal.mm@gmail.com
}

\begin{abstract}
The formulation of the problem in this study is: How is the influence of organizational commitment, work environment and job satisfaction on employee turnover intentions at Dinas Perikanan Kota Tanjungbalai. This study aims to determine the effect of organizational commitment, work environment and job satisfaction on employee turnover intentions. With total sampling technique, the sample in this study was 41 people. The results showed; Organizational commitment partially has a positive effect on employee turnover intentions of 3.882; The work environment partially has a positive influence on employee turnover intentions of 2,988; Job satisfaction partially has a positive effect on employee turnover intentions of 2.646; Organizational commitment, work environment and job satisfaction simultaneously have a positive and significant effect on employee turnover intentions of 24,881 .
\end{abstract}

Keywords : Organizational Commitment; Work environment; Job satisfaction; Turnover intention

ABSTRAK : Rumusan masalah dalam penelitian ini adalah : Bagaimana pengaruh komitmen organisasi, lingkungan kerja dan kepuasan kerja terhadap intensi turnover pegawai di Dinas Perikanan Kota Tanjungbalai. Penelitian ini bertujuan untuk mengetahui pengaruh komitmen organisasi, lingkungan kerja dan kepuasan kerja terhadap intensi turnover pegawai. Dengan teknik penarikan sampel secara Total Sampling maka sampel dalam penelitian ini sebanyak 41 orang. Hasil penelitian menunjukkan; Komitmen organisasi secara parsial memiliki pengaruh yang positif terhadap intensi turnover pegawai sebesar 3,882; Lingkungan kerja secara parsial memiliki pengaruh yang positif terhadap intensi turnover pegawai sebesar 2,988; Kepuasan kerja secara parsial memiliki pengaruh yang positif terhadap intensi turnover pegawai sebesar 2,646; Komitmen organisasi, lingkungan kerja dan kepuasan kerja secara simultan memiliki pengaruh yang positif dan signifikan terhadap intensi turnover pegawai sebesar 24,881 .

\section{Kata Kunci : Komitmen Organisasi; Lingkungan Kerja; Kepuasan Kerja; Iintensi Turnover}

\section{Pendahuluan}

Pada Dinas Perikanan Kota Tanjungbalai terdapat 3 golongan pegawai yaitu pegawai tetap, pegawai tidak tetap (PTT) dan pegawai UHL (upah haraian lepas). Fenomena yang terjadi di Dinas Perikanan Kota Tanjungbalai adalah ketidakamanan kerja yang dirasakan pegawai tidak tetap dan pegawai UHL karna kurangnya kesempatan karir yang akan didapatkan. Hal ini akan memicu pegawai supaya mencari peluang kesempatan karir yang lebih menjanjikan. Keinginan berpindah pegawai akan menjadi meningkat dan akan berdampak pada kinerja pegawai tersebut yang semakin menurun
Fenomena yang terjadi Dinas Perikanan Kota Tanjungbalai adalah ada beberapa pegawai yang merasakan ketidakamanan kerja namun ia tidak memiliki keinginan untuk meninggalkan pekerjaannya. Alasan beberapa pegawai ini tidak memiliki keinginan untuk meninggalkan pekerjaannya adalah kekhawatiran pegawai akan pekerjaan yang akan di dapatkannya tidak lebih baik dari pekerjaan sebelumnya. Selain itu rasa nyaman yg didapatkan di tempat kerjanya dikhawatirkan tidak bisa ia dapatkan lagi di tempat kerja yang baru. Oleh karna itu beberapa pegawai ini tetap menjaga komitmen 
organisasainya untuk tetap bertahan di tempat kerjanya sekarang

Maka dari itu apabila pegawai merasa aman atas pekerjaannya maka pegawai tersebut cenderung tidak akan meninggalkan pekerjaannya karna pekerjaan itu penting bagi dirinya dan pengembangan karirnya. Pegawai tersebut juga akan merasa aman terhadap pekerjaannya. Sumber daya manusia (SDM) merupakan satu-satunya aset penting organisasi yang dapat menggerakkan sumber daya lainnya. Sumber daya manusia dapat mempengaruhi efisiensi dan efektivitas organisasi (Simamora, 2012 : 99). Hal tersebutlah yang membuat Dinas Perikanan Kota Tanjungbalai sadar akan nilai investasi pegawai sebagai sumber daya manusia. Saat ini mengumpulkan tenaga kerja yang cakap dan berkinerja baik semakin sulit dilakukan, terlebih lagi mempertahankan yang sudah ada. Mereka harus memprioritaskan untuk menemukan, mempekerjakan, memotivasi, melatih, mengembangkan pegawai yang paling dekat dengan budaya organisasi dan performa yang dikehendaki, serta mempertahankan pegawai berkualitas (Pophal, 2016 : 71).

Pegawai dipandang sebagai aset instansi yang penting bagi Dinas Perikanan Kota Tanjungbalai, karena pegawai merupakan sumber daya yang dinamis dan selalu dibutuhkan dalam setiap kegiatan operasional pada Dinas Perikanan Kota Tanjungbalai. Oleh karenanya, instansi perlu melakukan pengelolaan SDM secara efisien dan efektif dengan menerapkan kebijakan SDM yang sesuai. Penerapan kebijakan yang tidak sesuai dapat berdampak buruk terhadap sikap kerja pegawai, seperti turnover. Turnover adalah perpindahan tenaga kerja dari dan ke sebuah instansi (Scott dalam Novliadi, 2017: 9). Salah satu cara untuk mengetahui penyebab turnover adalah menilai sejauh mana tingkat komitmen organisasi, lingkungan kerja dan job insecurity dari pegawai itu sendiri.

Luvy Kurniasari (2014) melakukan penelitian pada PT. Indo C. Hasil penelitian menunjukkan bahwa komitmen organisasi mempunyai berpengaruh positif dan signifikan terhadap turnover intentions begitu juga dengan jobinsecurity yang berpengaruh positif dan signifikan terhadap turnover intentions. Tingkat turnover pegawai yang tinggi merupakan ukuran yang sering digunakan sebagai indikasi adanya masalah yang mendasar pada organisasi.

Turnover pegawai dapat menelan biaya yang tinggi, Oleh karena itu organisasi perlu menguranginya sampai pada tingkat-tingkat yang dapat diterima. Namun demikian, mempertahankan tingkat perputaran sebesar nol adalah tidak realistis dan bahkan tidak dikehendaki. Berdasarkan pada hasil penelitian yang dilakukan oleh beberapa peneliti, penelitian ini akan melakukan pengujian kembali terhadap beberapa faktor yang diprediksi berpengaruh terhadap keinginan berpindah pegawai. Faktor-faktor tersebut adalah komitmen organisasi, lingkungan kerja dan job insecurity. Pegawai adalah aset berharga yang dimiliki Dinas Perikanan Kota Tanjungbalai, berkaitan dengan hal tersebut, sangatlah perlu diadakan penelitian secara spesifik mengenai rasa kepedulian instansi terhadap pegawai yang dimilikinya dan variabel lainnya yang berhubungan dengan pegawai tersebut agar dapat diketahui timbal balik yang dilakukan pegawai terhadap apa yang telah diberikan instansi.

Selain itu intensi turnover juga dipengaruhi oleh faktor kepuasan kerja. Robbins (2012 : 71) mengistilahkan kepuasan kerja sebagai sikap umum seseorang individu terhadap pekerjaannya, selanjutnya dijelaskan pula bahwa seseorang dengan kepuasan kerja yang tinggi menunjukkan sikap positif terhadap intensi turnover, sebaliknya seseorang yang tidak puas dengan pekerjaannya menunjukkan sikap yang negatif terhadap pekerjaan itu.

Para pegawai menyatakan ketidakpuasan mereka dalam hal pemberian reward and punishment terkait dengan data finger print. Diberlakukannya fingerprint sebenarnya sangat membantu pimpinan unit kerja masing-masing dalam mengontrol kedisiplinan bawahannya. Dengan adanya sanksi berupa potongan gaji yang terakumulasi setiap bulan, dinilai cukup efektif menekan tingkat keterlambatan di pagi hari dan mengurangi tingkat bolos di siang hari (pulang terlebih dahulu sebelum jam kerja berakhir). Akan tetapi aturan tersebut hanya merujuk pada jam kehadiran pagi hari dan jam pulang saja, sehingga pegawai yang bolos selama jam kerja tidak tersentuh sanksi potongan tersebut. Pemberlakuan aturan potong gaji tersebut juga dinilai kurang tepat sasaran. Tidak jarang yang terkena potongan 
malahan pegawai yang rajin dan kinerjanya bagus, hanya saja sering terlambat datang ke kantor dikarenakan alasan yang benar-benar penting (misal mengantar anak sekolah terlebih dahulu, rumahnya jauh dari kantor, dsb). Akhirnya yang bersangkutan pasrah ketika potongan gajinya terakumulasi banyak di setiap akhir bulan. Di samping itu sangat jarang pemberian reward bagi pegawai yang kinerjanya bagus.

Berdasarkan pemaparan Robbins (2012 : 71) tersebut di atas, para pegawai mengekspresikan ketidakpuasan dengan cara membicarakan kepada atasan agar kondisi tersebut dapat berubah. Lalu atasan menyampaikan hal tersebut kepada Bidang Pembinaan Pegawai BKD agar segera dibuat regulasi yang tepat.

Menurut Lee et al dalam (Susanti \& Palupinngdyah, $2016: 113)$ turnover intention merupakan kemungkinan atau kecenderungan pegawai untuk meninggalkan organisasi tempat dia bekerja sekarang, dan kecenderungan ini akan mengarah kepada perilaku turnover. Seseorang yang memiliki turnover intention yang tinggi maka seseorang tersebut akan berfikir untuk mencari pekerjaan lain yang lebih baik dan meninggalkan organisasi tersebut. Menurut Widodo dalam (Susanti \& Palupinngdyah, 2016 : 78) dampak dari turnover intention adalah penurunan kinerja pegawai, sehingga perlu diketahui faktor- faktor yang menyebabkan turnover intention supaya turnover intention dapat ditekan.

Sikap yang muncul dalam individu ketika muncul turnover intention adalah adanya keinginan pegawai untuk mencari pekerjaan baru yang lebih baik ditempat lain ataupun rencana pegawai untuk meninggalkan organisasi atau instansi dalam waktu tiga bulan, enam bulan, satu tahun atau dua tahun yang akan datang (Widodo,2010 : 175). Ketika pegawai tersebut sudah berfikir ingin meninggalkan organisasinya dan mencari lowongan pekerjaan yang lebih baik namun apabila kesempatan untuk pindah tidak tersedia atau pekerjaan yang tersedia tidak lebih baik dari pekerjaan yang sebelumnya maka hal ini akan berdampak terhadap perilaku di tempat kerjanya. Perilaku yang menggambarkan pegawai tersebut seperti datang terlambat, sering bolos, kurang antusias terhadap pekerjaannya sehingga hal ini akan berdampak pada hasil kerja yang terus menurun.

Jadi penelitian mengenai turnover intention masih terdapat kesimpangsiuran hasil penelitian sehingga perlu dilakukan penelitian. Berdasarkan pada hasil penelitian yang dilakukan oleh beberapa peneliti, penelitian ini akan melakukan pengujian kembali terhadap beberapa faktor yang diprediksi berpengaruh terhadap keinginan berpindah pegawai. Faktorfaktor tersebut adalah komitmen organisasi, lingkungan kerja dan kepuasan kerja. Pegawai adalah aset berharga yang dimiliki Dinas Perikanan Kota Tanjungbalai, berkaitan dengan hal tersebut, sangatlah perlu diadakan penelitian secara spesifik mengenai rasa kepedulian instansi terhadap pegawai yang dimilikinya dan variabel lainnya yang berhubungan dengan pegawai tersebut agar dapat diketahui.

\subsection{Rumusan Masalah}

Berdasarkan latar belakang masalah tersebut diatas, maka yang menjadi rumusan masalah dalam penelitian ini adalah :

a. Bagaimana pengaruh komitmen organisasi terhadap intensi turnover pegawai di Dinas Perikanan Kota Tanjungbalai ?

b. Bagaimana pengaruh lingkungan kerja terhadap intensi turnover pegawai di Dinas Perikanan Kota Tanjungbalai ?

c. Bagaimana pengaruh kepuasan kerja terhadap intensi turnover pegawai di Dinas Perikanan Kota Tanjungbalai ?

d. Bagaimana pengaruh komitmen organisasi, lingkungan kerja dan kepuasan kerja terhadap intensi turnover pegawai di Dinas Perikanan Kota Tanjungbalai ?

\subsection{Batasan Masalah}

Dalam penelitian ini hanya meneliti tentang bagaimana pengaruh komitmen organisasi, lingkungan kerja dan job insecurity terhadap intensi turnover pegawai di Dinas Perikanan Kota Tanjungbalai.

\subsection{Hioptesis}

Berdasarkan kerangka pemikiran di atas maka dibutuhkan suatu pengujian hipotesis untuk mengetahui apakah terdapat hubungan antara variabel independent terhadap variabel dependent. Hipotesis adalah jawaban sementara yang secara teoritis dianggap 
paling mungkin dan paling tinggi tingkat kebenarannya.

Menurunt Narimawati (2013 : 73) “ Hipotesis dapat dikatakan sebagai pendugaan sementara mengenai hubungan antar variabel yang akan diuji kebenarannya".

Karena sifatnya dugaan, maka hipotesis hendaknya mengandung implikasi yang lebih jelas terhadap pengujian hubungan yang akan dinyatakan. Berdasarkan kerangka pemikiran diatas, maka penulis berasumsi mengambil keputusan sementara (hipotesis) bahwa sebagai berikut:

a. Komitmen organisasi memiliki pengaruh terhadap intensi turnover pada Dinas Perikanan Kota Tanjungbalai

b. Lingkungan kerja memiliki pengaruh terhadap intensi turnover pada Dinas Perikanan Kota Tanjungbalai

c. Kepuasan kerja memiliki pengaruh terhadap intensi turnover pada Dinas Perikanan Kota Tanjungbalai

d. Komitmen organisasi, lingkungan kerja dan kepuasan kerja memiliki pengaruh terhadap intensi turnover pada Dinas Perikanan Kota Tanjungbalai.

\subsection{Tujuan Penelitian}

Tujuan yang hendak dicapai dalam penelitian ini yaitu:

a. Untuk mengetahui pengaruh komitmen organisasi terhadap intensi turnover pegawai di Dinas Perikanan Kota Tanjungbalai.

b. Untuk mengetahui pengaruh lingkungan kerja terhadap intensi turnover pegawai di Dinas Perikanan Kota Tanjungbalai ?

c. Untuk mengetahui pengaruh kepuasan kerja terhadap intensi turnover pegawai di Dinas Perikanan Kota Tanjungbalai ?

d. Untuk mengatahui pengaruh komitmen organisasi, lingkungan kerja dan kepuasan kerja terhadap intensi turnover pegawai di Dinas Perikanan Kota Tanjungbalai ?

\section{Metode Penelitian}

\subsection{Populasi}

Tabel 2. Kerangka Sampel Berdasarkan Jabatan Thn. 2020
Dalam suatu penelitian, populasi yang dipilih mempunyai hubungan yang erat dengan masalah yang diteliti. Populasi atau unverse adalah jumlah keseluruhan unit analisis yang ciricirinya akan diduga, Singarimbun \& Effendi (2012 : 126). Dalam penelitian ini yang menjadi populasi adalah seluruh pegawai Dinas Perikanan Kota Tanjungbalai yang berjumlah 43 orang dan dapat dijelaskan dengan kerangka populasi sebagai berikut :

Tabel 1. Kerangka Populasi Berdasarkan Jabatan Thn. 2020

\begin{tabular}{|r|l|c|}
\hline No & Jabatan & Jlh \\
\hline 1 & Kepala Dinas & 1 \\
\hline 2 & Sekretaris & 1 \\
\hline 3 & Kepala Bidang & 1 \\
\hline 4 & Bendahara & 2 \\
\hline 5 & Ka.Seksi & 2 \\
\hline 6 & Bagian Pengadministrasi & 7 \\
\hline 7 & Bagian Pengelola & 3 \\
\hline 8 & Analis dan Peramu Benih & 2 \\
\hline 9 & Pelaksana Jabatan & 14 \\
\hline 10 & Honorer & 10 \\
\hline Jumlah & $\mathbf{4 3}$ \\
\hline \multicolumn{2}{|l|}{ Sumber: Dinas Perikanan Kota Tanjungbalai-2020 }
\end{tabular}

\subsection{Sampel}

Sampel merupakan bagian dari elemenelemen populasi yang hendak diteliti. Adapun ide dasar dari pengambilan sampel adalah bahwa dengan menyeleksi bagian dari elelmen-elemen populasi, kesimpulan tentang keseluruhan populasi diharapkan dapat diperoleh, Cooper \& Pamela (2011 : 95). Keunggulan ekonomis pengambilan sampel adalah biayanya lebih murah dan memberikan hasil yang lebih cepat. Dengan teknik penarikan sampel secara Total Sampling maka sampel dalam penelitian ini adalah seluruh populasi yaitu Dinas Perikanan Kota Tanjungbalai sebanyak 41 orang. Karena Kepala Dinas dan Peniliti Sebagai Kepala Bidang Pemberdayaan Masyarakat Perikanan tidak ikut di teliti dalam penelitian ini.

\begin{tabular}{|r|l|c|c|c|}
\hline No & Jabatan & Jlh Populasi & Jlh. Sampel & Keterangan \\
\hline 1 & Kepala Dinas & 1 & - & Tidak \\
\hline 2 & Sekretaris & 1 & 1 & Di teliti \\
\hline 3 & Kepala Bidang & 1 & - & Peneliti \\
\hline 4 & Bendahara & 2 & 2 & Di teliti \\
\hline
\end{tabular}




\begin{tabular}{|r|l|c|c|c|}
\hline No & Jabatan & Jlh Populasi & Jlh. Sampel & Keterangan \\
\hline 5 & Ka.Seksi & 2 & 2 & Di teliti \\
\hline 6 & Bagian Pengadministrasi & 7 & 7 & Di teliti \\
\hline 7 & Bagian Pengelola & 3 & 3 & Di teliti \\
\hline 8 & Analis dan Peramu Benih & 2 & 2 & Di teliti \\
\hline 9 & Pelaksana Jabatan & 14 & 14 & Di teliti \\
\hline 10 & Honorer & 10 & 10 & Di teliti \\
\hline \multicolumn{2}{r|}{ Jumlah } & $\mathbf{4 3}$ & $\mathbf{4 1}$ & \\
\hline
\end{tabular}

Sumber: Dinas Perikanan Kota Tanjungbalai - 2020

\subsection{Uji Normalitas}

Pengujian normalitas data bertujuan untuk melihat normal tidaknya sebaran data yang akan dianalisis. Model regresi yang baik adalah distribusi normal atau mendekati normal. Untuk melihat normalitas data ini digunakan pendekatan grafik yaitu Normality Probability Plot.

Deteksi normalitas dengan melihat penyebaran data (titik) pada sumbu diagonal dari grafik. Menurut Santoso (2014:214), dasar pengambilan keputusan adalah:

a. Jika data menyebar disekitar garis diagonal dan mengikuti arah garis diagonal, maka model regresi memenuhi asumsi normalitas.

b. Jika data menyebar jauh dari garis diagonal dan atau tidak mengikuti arah garis diagonal, maka model regresi tidak memenuhi asumsi normalitas. Pada output SPSS versi 24.00 bagian normal P-P Plot of Regresion Standardized Residual, dapat dijelaskan bahwa data-data (titik-titik) cenderung lurus mengikuti garis diagonal sehingga data dalam penelitian ini cenderung berdistribusi normal, seperti terlihat pada gambar dibawah ini.

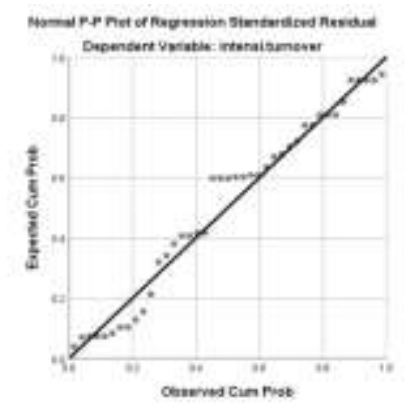

Gambar 1. Normalitas Data

\subsection{Uji Multikolinearitas}

Pengujian multikolinearitas dilakukan untuk melihat apakah pada model regresi ditemukan adanya korelasi antara variabel bebas. Jika terjadi korelasi, maka dinamakan terdapat problem multikolinearitas. Cara mendeteksinya adalah dengan melihat nilai Variance Inflation Factor (VIF). Menurut Santoso (2014:203), pada umumnya jika VIF lebih besar dari 5, maka variabel bebas tersebut mempunyai persoalan multikolinearitas dengan variabel bebas lainnya.

Pada ouput SPSS bagian Coefficient, semua angka VIF berada dibawah 5, hal ini menunjukan tidak terjadi multikolinearitas, seperti dapat dilihat pada tabel dibawah ini.

Tabel 3. Uji Multikolinearitas

\begin{tabular}{|l|l|r|r|}
\hline \multicolumn{3}{|c|}{ Coefficients $^{\text {a }}$} \\
\hline \multicolumn{2}{|l|}{ Model } & \multicolumn{2}{c|}{$\begin{array}{c}\text { Collinearity } \\
\text { Statistics }\end{array}$} \\
\cline { 2 - 4 } \multicolumn{2}{|l|}{} & Tolerance & VIF \\
\hline \multirow{3}{*}{1} & (Constant) & .780 & 1.281 \\
\cline { 2 - 4 } & komitmen.organisasi & .739 & 1.353 \\
\cline { 2 - 4 } & lingkungan.kerja & .686 & 1.457 \\
\cline { 2 - 4 } & kepuasan.kerja & \multicolumn{3}{|c|}{ a. Dependent Variable: } \\
\hline
\end{tabular}

intensi.turnover

\subsection{Uji Heteroskedastisitas}

Pengujian heteroskedastisitas bertujuan untuk melihat apakah dalam sebuah model regresi terjadi ketidaksamaan varians dari residual yang merupakan suatu pengamatan ke pengamatan yang lainnya. Jika varians dari residual yang merupakan suatu pengamatan ke pengamatan yang lain bernilai tetap, maka hasil data disebut homoskedastisitas dan jika varians berbeda atau bernilai tidak tetap maka disebut heteroskedastisitas. Model regresi yang baik adalah model yang bernilai tetap atau homoskedastisitas atau tidak terjadi heteroskedastisitas. 
Deteksi heteroskedastisitas dilakukan dengan cara melihat ada tidaknya pola tertentu pada data yang diolah. Menurut Santoso (2014:208), dasar pengambilan keputusannya adalah:

a. Jika pola tertentu seperti titik-titik yang ada membentuk suatu pola tertentu yang teratur, maka terdapat situasi heteroskedastisitas.

b. Jika tidak ada pola yang jelas, serta titiktitik menyebar diatas dan dibawah angka nol pada sumbu Y, maka tidak terjadi heteroskedastisitas.

Pada output SPSS dibagian Scatrerplot, terlihat titk-titik menyebar secara acak, tidak membentuk sebuah pola tertentu yang jelas, serta tersebar baik diatas maupun dibawah angka nol pada sumbu Y. Hal ini berarti tidak terjadi heterskedastisitas pada model regresi, sehingga model regresi layak dipakai. Pola Scatterplot dapat dilihat pada gambar dibawah ini.

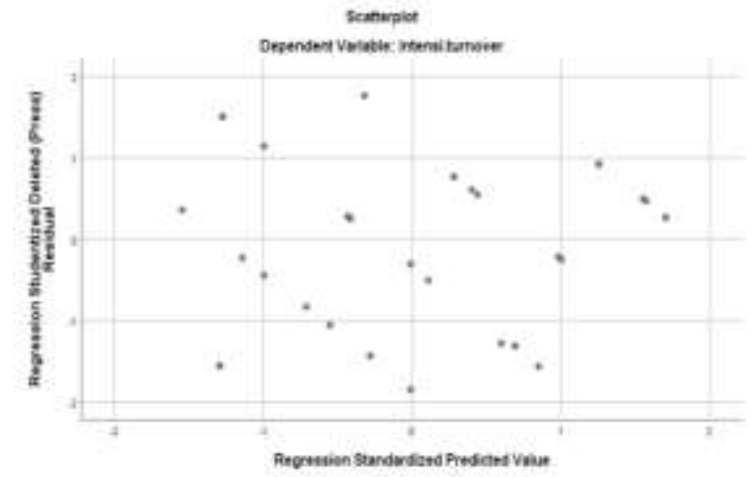

Gambar 2. Uji Heteroskedastitas

\section{Evaluasi Data (Analisa Regresi Linier Berganda ) \\ 3.1 Pengujian Hipotesis}

Dalam evaluasi data ini penulis akan melakukan pengujian hipotesis, baik secara partial ataupun secara simultan. Selanjutnya untuk mempermudah dalam evaluasi data ini, maka penulis mencari niali-nilai yang dibutuhkan dengan menggunakan perangkat lunak komputer yaitu program SPSS V.24.00 for windows dengan hasil data sebagai berikut:

Tabel 4. Hasil Uji Statistik Keofesien Regresi

\begin{tabular}{|c|c|c|c|c|c|c|}
\hline \multicolumn{7}{|c|}{ Coefficients $^{\mathbf{a}}$} \\
\hline \multirow{2}{*}{\multicolumn{2}{|c|}{ Model }} & \multicolumn{2}{|c|}{$\begin{array}{l}\text { Unstandardized } \\
\text { Coefficients }\end{array}$} & $\begin{array}{c}\text { Standardized } \\
\text { Coefficients }\end{array}$ & $\mathrm{t}$ & Sig. \\
\hline & & B & Std. Error & Beta & & \\
\hline \multirow{5}{*}{1} & (Constant) & 5.504 & 4.737 & & & \\
\hline & & & & & 1.162 & 253 \\
\hline & komitmen.organisasi & .405 & .106 & .410 & 3.822 & .000 \\
\hline & lingkungan.kerja & 274 & .092 & .329 & 2.988 & .005 \\
\hline & kepuasan.kerja & .256 & .097 & .302 & 2.646 & .012 \\
\hline
\end{tabular}

a. Dependent Variable: intens .turnover

Berdasarkan tabel 4 diatas dapat dibuat persamaan regresi sebagai berikut: $\mathrm{Y}=\mathrm{a}+$ $\mathrm{b} 1 \mathrm{X} 1+\mathrm{b} 2 \mathrm{X} 2+\mathrm{b} 3 \mathrm{X} 3+\varepsilon$

$$
\mathrm{Y}=5,504+0,405 X_{1}+0,274 X_{2}+0,256 X_{3}+
$$

$\varepsilon$

Persamaan diatas dijelaskan bahwa koefesien komitmen organisasi mempunyai nilai positif yaitu 0,405 , hal ini menunujukan bahwa variabel komitmen organisasi mempunyai pengaruh positif terhadap intensi turnover.

Berdasarkan persamaan diatas bahwa koefesien lingkungan kerja memiliki nilai positif yaitu 0,274. Hal ini menunjukan bahwa variabel lingkungan kerja mempunyai pengaruh positif terhadap intensi turnover.

Berdasarkan persamaan diatas bahwa koefesien kepuasan kerja memiliki nilai positif yaitu 0,256 . Hal ini menunjukan bahwa variabel kepuasan kerja juga mempunyai pengaruh positif terhadap intensi turnover.

\subsection{Pengujian Secara Simultan (Uji F)}

Untuk melihat hasil seberapa besar pengaruh yang di berikan variabel independen terhadap dependen secara simultan ( bersamasama ) pada penelitian ini maka dapat di jelaskan pada tabel di bawah ini : 
Tabel 5. Hasil Uji Statistik Secara Simultan

\begin{tabular}{|c|c|c|c|c|c|c|}
\hline \multicolumn{2}{|c|}{ Model } & Sum of Squares & $\mathrm{df}$ & Mean Square & $\mathrm{F}$ & Sig. \\
\hline \multirow{3}{*}{1} & Regression & 35.451 & 3 & 11.817 & 24.881 & $.000^{\mathrm{b}}$ \\
\hline & Residual & 17.573 & 37 & .475 & & \\
\hline & Total & 53.024 & 40 & & & \\
\hline
\end{tabular}

Pada tabel 5 diatas terlihat bahwa nilai Fhitung adalah 24,881 dan nilai signifikansi 0,000. Diketahui nilai $F$ tabel dengan tingkat kepercayaan $95 \% \quad(\alpha: 0,05)$ adalah 2,840. Oleh karena itu nilai Fhitung > Ftabel $(24,881$ > 2,840 ) maka $\mathrm{H}_{\mathrm{O}}$ ditolak dan menerima hipotesis dalam penelitian ini yaitu bahwa komitmen organisasi, lingkungan kerja dan kepuasan kerja secara simultan memiliki pengaruh yang positif dan signifikan terhadap intensi turnover pegawai Dinas Perikanan Kota
Tanjungbalai sebesar 24,881, Oleh karena itu maka Dinas Perikanan Kota Tanjungbalai harus lebih aktif dalam meningkatkan dan menumbuh kembangkan komitmen organisasi, lingkungan kerja dan kepuasan kerja para pegawainya secara personal ataupun secara menyeluruh sehingga pegawai merasa nyaman dan tidak akan pernah meninggalkan instansi

\subsection{Pengujian Secara Parsial (Uji t)}

Tabel 6. Hasil Uji Parsial Variabel X Terhadap Y

\begin{tabular}{|c|c|c|c|c|c|c|}
\hline \multicolumn{7}{|c|}{ Coefficients $^{\mathbf{a}}$} \\
\hline \multirow{2}{*}{\multicolumn{2}{|c|}{ Model }} & \multicolumn{2}{|c|}{$\begin{array}{l}\text { Unstandardized } \\
\text { Coefficients }\end{array}$} & \multirow{2}{*}{$\begin{array}{l}\text { Standardized } \\
\text { Coefficients } \\
\text { Beta }\end{array}$} & \multirow[t]{2}{*}{$\mathrm{t}$} & \multirow[t]{2}{*}{ Sig. } \\
\hline & & $\mathrm{B}$ & Std. Error & & & \\
\hline \multirow{5}{*}{1} & (Constant) & 5.504 & 4.737 & & & \\
\hline & & & & & 1.162 & 253 \\
\hline & komitmen.organisasi & 405 & 106 & .410 & 3.822 & .000 \\
\hline & lingkungan.kerja & 274 & .092 & .329 & 2.988 & .005 \\
\hline & kepuasan.kerja & .256 & .097 & .302 & 2.646 & .012 \\
\hline
\end{tabular}

\subsubsection{Pengaruh Komitmen Organisasi Terhadap Intensi Turnover}

Untuk mengetahui secara parsial pengaruh komitmen organisasi terhadap intensi turnover dapat dilihat pada tebel 6 diatas. Berdasarkan tabel tersebut diperoleh nilai thitung sebesar 3,882 dan nilai signifikansi 0,000 . Sedangkan nilai tabel pada tingkat kepercayaan 95\% ( $\alpha: 0,05)$ adalah 2,021. Oleh karena itu nilai thitung $>$ tabel $(4,082$ $>$ 2,021) maka $\mathrm{H}_{\mathrm{O}}$ ditolak dan menerima hipotesis dalam penelitian ini yaitu komitmen organisasi secara parsial memiliki pengaruh yang positif terhadap intensi turnover pegawai Dinas Perikanan Kota Tanjungbalai sebesar 3,882.

Dengan demikian dapat di simpulkan bahwa komitmen organisasi sangat perlu untuk di tingkatkan karena harapan pegawai terhadap organisasi. Jika harapan tersebut terpenuhi, maka pegawai akan puas dan mempunyai sikap positif, sehingga pegawai ttep ingin bertahan terhadap instansi.

\subsubsection{Pengaruh Lingkungan Kerja \\ Terhadap Intensi Turnover}

Untuk mengetahui secara parsial pengaruh lingkungan kerja terhadap intensi turnover, dapat dilihat pada tebel 6 diatas. Berdasarkan tabel tersebut diperoleh nilai thitung sebesar 2,988 dan nilai signifikansi 0,005 . Sedangkan nilai tabel pada tingkat kepercayaan 95\% ( $\alpha: 0,05)$ adalah 2,021. Oleh karena itu nilai thitung > tabel ( 2,988 $>$ 2,021 ) maka $\mathrm{H}_{\mathrm{O}}$ ditolak dan menerima hipotesis dalam penelitian ini yaitu lingkungan kerja secara parsial memiliki pengaruh yang positif terhadap intensi turnover pegawai Dinas Perikanan Kota Tanjungbalai sebesar 2,988 . 
Dengan demikian bahwa lingkungan kerja juga menjadi salah satu factor terhadap intensi turnover, Hal yang paling mungkin dilakukan oleh instansi adalah menjaga mereka agar tetap merasa nyaman dengan lingkungan kerja di instansi. Tidak hanya lingkungan kerja fisik tetapi dalam hal psikologisnya pun harus diperhatikan karena Lingkungan kerja yang kondusif memberikan rasa aman dan memungkinkan pegawai untuk dapat bekerja optimal dan pada akhirnya pegawai tersebut akan betah di tempat kerjanya.

\subsubsection{Pengaruh Kepuasan Kerja Terhadap Intensi Turnover}

Untuk mengetahui secara parsial pengaruh kepuasan kerja terhadap intensi turnover, dapat dilihat pada tebel 6 diatas. Berdasarkan tabel tersebut diperoleh nilai thitung sebesar 2,646 dan nilai signifikansi 0,012 . Sedangkan nilai ttabel pada tingkat kepercayaan 95\% $(\alpha: 0,05)$ adalah 2,021. Oleh karena itu nilai thitung > tabel ( 2,646 > 2,021) maka $\mathrm{H}_{\mathrm{O}}$ ditolak dan menerima hipotesis dalam penelitian ini yaitu variabel kepuasan kerja secara parsial memiliki pengaruh yang positif terhadap intensi turnover pegawai Dinas Perikanan Kota Tanjungbalai sebesar 2,646.

Dengan kata lain kepuasan kerja juga membuktikan bahwa individu yang merasa terpuaskan dengan pekerjaannya cenderung untuk bertahan dalam organisasi. Sedangkan individu yang merasa kurang terpuaskan dengan pekerjaannya akan memilih keluar dari organisasi. Oleh karena itu instansi di harus bisa menciptakan respon-respon efektif seperti menciptakan perasaan kepuasan seperti pemberian insentif, kenaikan gaji dan jabatan yang baru mungkin akan menuju ke intensi dimana pegawai untuk tetap bertahan di instansi

\subsection{Uji Koefisien Determinasi $\left(R^{2}\right)$}

Uji determinan adalah uji yang dilakukan untuk mengetahui seberapa besar pengaruh variabel independent ( komitmen organisasi, lingkungan kerja dan kepuasan kerja ) terhadap variabel dependent ( intensi turnover ). Untuk melihat hasil uji determinan maka dapat diketahui nili $\mathrm{R}$ Square atau koefesien determinasi dan dapat dilihat dibawah ini.

Tabel 7. Model Summary

\begin{tabular}{|l|c|c|c|c|}
\hline Model & $\mathrm{R}$ & $\mathrm{R}$ Square & Adjusted R Square & Std. Error of the Estimate \\
\hline 1 & & & & \\
\hline a. Predictors: (Constant), kepuasan.kerja, komitmen.organisasi, lingkungan.kerja \\
\hline \multicolumn{2}{|l}{ b. Dependent Variable: intensi.turnover } \\
\hline
\end{tabular}

Nilai R Square pada tabel 7. diatas adalah 0,669 . Hal ini menunjukan bahwa $66,90 \%$ variabel intensi turnover pegawai Dinas Perikanan Kota Tanjungbalai dapat di jelaskan oleh variabel komitmen organisasi, lingkungan kerja dan kepuasan kerja sedangkan sisanya sebesar $33,10 \%$ di pengaruhi oleh variabel lain yang tidak ikut di teliti.

\section{Kesimpulan}

a. Komitmen organisasi secara parsial memiliki pengaruh yang positif terhadap intensi turnover pegawai Dinas Perikanan Kota Tanjungbalai sebesar 3,882

b. Lingkungan kerja secara parsial memiliki pengaruh yang positif terhadap intensi turnover pegawai Dinas Perikanan Kota Tanjungbalai sebesar 2,988

c. Kepuasan kerja secara parsial memiliki pengaruh yang positif terhadap intensi turnover pegawai Dinas Perikanan Kota Tanjungbalai sebesar 2,646

d. Komitmen organisasi, lingkungan kerja dan kepuasan kerja secara simultan memiliki pengaruh yang positif dan signifikan terhadap intensi turnover pegawai Dinas Perikanan Kota Tanjungbalai sebesar 24,881

e. Diketahui nilai R Square sebesar 0,669. Hal ini menunjukan bahwa $66,90 \%$ variabel intensi turnover pegawai Dinas Perikanan Kota Tanjungbalai dapat di jelaskan oleh variabel komitmen organisasi, lingkungan kerja dan kepuasan kerja sedangkan sisanya sebesar $33,10 \%$ di pengaruhi oleh variabel lain yang tidak ikut di teliti.

\section{DAFTAR PUSTAKA}

Abbasi, Sami, M., Hollman, K. W. 2018. Turnover : The Real Bottom Line. 
Journal of PublicPersonnel Management. Vol 29(3). p 333-342

Abdullah, M. 2014. Manajemen dan Evaluasi kinerja Karyawan. Yogyakarta: Penerbit Aswaja Pressindo.

Ahmad Zulva Adi \& Sri Langgeng Ratnasari. 2015. Pengaruh Komitmen Organisasi, lingkungan kerja dan Kepuasan Kerja Terhadap intensi turnover Karyawan Pada Perbankan Syariah Di Kota Batam. Jurnal.

Ajzen, I. 2016. Attitudes, Personality, and Behavior. Chicago: Dorsey Press. Allen, N. J., \& Mayer, J. P. 2011. The measurement and antecedent of

affective, continuance, and normative commitmen to organization. Journal of Occupational Psychology Vol. 63, 1 - 18.

Ali, N., \& Baloch, Q. B. 2010. Job satisfaction and employee turnover intention (Case study of NWFP Pakistan based banking sector). Interdicilinary Journal of Contemporary Research Business. Vol. 2, No.5: 39-66

Ancok, D. 2015. Teknik Penyusunan Skala Pengukuran. Yogyakarta: Pusat Penelitian Kependudukan UGM.

Azwar, S. 2017. Metode Penilitan. Yogyakarta: Pustaka Pelajar.

Bashaw, R., \& Grant, E. S. 2014. Exploring the distinctive nature of work commitments: Their relationship with personal characteristics, job performance, and propensity to leave. Journal of Personal Selling and Sales Management, 14(2), $41-56$.

Chen, Z.X., Francesco, A.M. 2017. Employee Demography,

Organizational Commitment, And Turnover Intentions In China: Do Cultural DifferencesMatter?. Human Relations, 53, 869-887.

Cooper, Donald R, dan Pamela S. Schindler, 2011. Metode Riset Bisnis. Jakarta: PT Media Global Edukasi.

Darmawati, D, dkk. 2016. Pengaruh Karakteristik Perusahaan dan Faktor Regulasi terhadap Kualitas Implementasi Corporate Governance. Simposium Nasional Akuntansi IX. Padang.

Greenhalgh, L., dan Z. Rosenblatt. 2014. Job Insecurity; Towards Conceptual Clarity. Academy of Management Review, 9 (3), p. $438-448$
Halimah, et.al. 2016. Pengaruh Semangat Kerja terhadap Efektivitas Kerja Pegawai di Kantor Kecamatan Kaliorang Kabupaten Kutai Timur. E- Journal Administrasi Negara Vol 2 No 4

Hanafi, Bayu Dwilaksono \& Yohana, Corry. 2017. Pengaruh Motivasi, Dan Lingkungan Kerja, Terhadap Kinerja Karyawan, Dengan Kepuasan Kerja Sebagai Variabel Mediasi Pada PT BNI Lifeinsurance. Jurnal Pendidikan Ekonomi dan Bisnis (JPEB),5 (1), h. 73-89.

Hanafiah, Mohammad. 2014. Pengaruh Kepuasan Kerja Dan Ketidakamanan Kerja (Job Insecurity) dengan intensi pindah kerja (Turnover) Pada Karyawan PT. Buma Desa Suaran Kecamatan Sambaliung Kabupaten Berau. Ejournal. Psikologi. Fisip-unmul. Vol.1No3.

Handoko, T. Hani. 2017. Manajemen Sumber Daya Manusia. Yogyakarta: BPFE.

Kansil, C.S.T. 2011. Manajemen Sumber Daya Manusia. Jakarta: Pradnya Paramitha.

Kurniasari, Devi dan Abdul Halim. 2014. Pengaruh Lingkungan Kerja dan Iklim Organisasi Terhadap Komitmen Organisasi Melalui Kepuasan Kerja Karyawan Pada Dinas Pasar Unit Pasar Tanjung Kabupaten Jember, Jurnal Ilmu Ekonomi, Vol. 8, No.2.

Malik dkk. 2010. Human Development Report. New York: The Human Development Programme.

Meyer, J. P, et. Al. 2011.Commitment in the Workplaces: Theory, Research, and Application. Thousand Oaks, CA: Sage.

Maulana, 2017. Kepemimpinan

Transformasional Dalam Birokrasi Pemerintahan. Edisi Pertama. Jakarta: Multicerdas Publis.

Narimawati, Umi. 2013. Riset Manajemen Sumber Daya Manusia Aplikasi \& Contoh Perhitunganya. Jakarta. Agung Media.

Ni Luh Mita Sri Devi \& Gede Adnyana Sudibia. 2015. Analisis Pengaruh Job insecurity dan lingkungan kerja Terhadap kepuasan kerja dan Turnover Intention: (Studi Pada Karyawan Kontrak Di Bali Dynasty Resort). Jurnal 
Nisa, H. D. W., dkk. 2015. Hubungan Antara Iklim Organisasi Dengan Intensi Turnover Pada Karyawan. Jurnal. Malang: Universitas Muhammadiyah.

Nitisemito, Alex. 2012. Manajemen Sumber Daya Manusia. Bandung: Remaja Rosdakarya.

Novliadi, F. 2017. Intensi Turnover Karyawan Ditinjau Dari Budaya Perusahaan dan Kepuasan Kerja. Makalah. Program Studi Psikologi Fakultas Kedokteran Universitas Sumatera Utara, Medan.

Nugraha, Firnawan Ajie. 2010. Pengaruh Kepemimpinan, Motivasi, Pelatihan dan Lingkungan Kerja Terhadap Kinerja Karyawan Pada perusahaan Textile PT. Kosoema Putra Klaten Jurnal Ekonomi dan Bisnis Jurnal volume, 4 No 10. Purba, S. 2014. Prilaku Organisai. Bandung: Alfabeta.

Putrianti, Arin Dewi. 2014. Pengaruh Kompensasi dan Motivasi Kerja Terhadap Turnover Intention. Skripsi. Malang: Universitas Brawijaya

Ramadhani, P. E. 2011. Hubungan Antara Persepsi Terhadap Lingkungan Psikososial Kerja Dengan Komitmen Organisasi. Skripsi (tidak diterbitkan). Surakarta : Fakultas Psikologi UMS.

Ridlo, I. A. 2012. Turn Over Karyawan "Kajian Literatur". Surabaya: Public Health Movement.

Robbins, P Stephen dan Timothy A. Judge. 2012. Prilaku Organisasi. Jakarta: Salemba Empat.

Robbins, Stephen P. 2015. Perilaku Organisasi. Jakarta: Salemba Empat.

Salancik, Gerald R. 2017. Commitment and the Control of Organizational Behavior and Belief, Psychological Dimensions of Organizational Behavior, ed.:Barry $\mathrm{M}$. Staw. New Jersey: Prentice Hall, Inc.

Schultz, D. \& Schultz, E. S. 2010. Psychology and work today (10 edition). New York: Pearson.

Sedarmayanti. 2012. Manajemen Sumber Daya Manusia Strategik. Bogor: Ghalia Indonesia.

Simamora, Henry. 2012. Birokrasi. Edisi 1. Yogyakarta: STIE YKP.

Singarimbun, Masri dan Sofian Effendi. 2012. Metode Penelitian Survei. Jakarta: LP3ES.
Sopiah. 2016. Prilaku Organisasi. Yogyakarta: Andi Ofset.

Spector. 2012. Job satisfaction: Application, assessment, causes and consequences. Thousand Oaks, CA,Sage Publications, Inc.

Triaryati, N. 2013. Pengaruh Adaptasi Kebijakan Mengenai Work Family Issue Terhadap Absen dan Turnover. Jurnal Manajemen dan Kewirausahaan, Vol. 5 (1).

Trenggono. 2018. Metode Penelitian Manajemen. Jakarta: Rajawali Pers. Widjaja, et.al. 2012. Manajemen Suatu Pengantar. Jakarta: Rineka Cipta.

Wismora \& Muchtar A.F, 2014. Strategi Memenangkan Persaingan Usaha Dengan Menyusun Business Plan. Jakarta : PT. Elex Media Komputindo Kompas Gramedia.

Zurnali, Cut. 2010. Knowledge Worker: Kerangka Riset Manajemen Sumber Daya Manusia Masa Depan. Bandung: Penerbit Unpad Press. 